\title{
Altered Auditory P300 Performance in Parents with Attention Deficit Hyperactivity Disorder Offspring
}

\author{
Mei Hung Chi ${ }^{1}$, Ching-Lin Chu ${ }^{1,2,3}$, I Hui Lee ${ }^{1}$, Yi-Ting Hsieh ${ }^{1}$, Ko Chin Chen ${ }^{1}$, Po See Chen ${ }^{1,3}$, Yen Kuang Yang ${ }^{1,3,4}$ \\ ${ }^{1}$ Department of Psychiatry, National Cheng Kung University Hospital, College of Medicine, National Cheng Kung University, Tainan, \\ ${ }^{2}$ Department of Educational Psychiatry \& Counseling, National Pingtung University, Pingtung, ${ }^{3}$ Institute of Behavioral Medicine, College of \\ Medicine, National Cheng Kung University, Tainan, ${ }^{4}$ Department of Psychiatry, National Cheng Kung University Hospital, Dou-Liou Branch, \\ Yunlin, Taiwan
}

\begin{abstract}
Objective: Altered event-related potential (ERP) performances have been noted in attention deficit hyperactivity disorder (ADHD) patients and reflect neurocognitive dysfunction. Whether these ERP alterations and correlated dysfunctions exist in healthy parents with ADHD offspring is worth exploring.

Methods: Thirteen healthy parents with ADHD offspring and thirteen healthy controls matched for age, sex and years of education were recruited. The auditory oddball paradigm was used to evaluate the P300 wave complex of the ERP, and the Wechsler Adult Intelligence Scale-Revised, Wisconsin Card Sorting Test, and continuous performance test were used to measure neurocognitive performance.

Results: Healthy parents with ADHD offspring had significantly longer auditory P300 latency at Fz than control group. However, no significant differences were found in cognitive performance.

Conclusion: The presence of a subtle alteration in electro-neurophysiological activity without explicit neurocognitive dysfunction suggests potential candidate of biological marker for parents with ADHD offspring.
\end{abstract}

KEY WORDS: Attention deficit disorder with hyperactivity; Cognition; Evoked potentials; P300; Parents.

\section{INTRODUCTION}

Attention deficit hyperactivity disorder (ADHD) is the most common neurodevelopmental illness of childhood, with influences continuing to adulthood if not being appropriately treated. Relevant research exploring the pathophysiology is ongoing, and neuroelectrophysiological techniques, such as brain event-related potential (ERP), have been widely used. Previous studies have indicated altered ERPs in subject with ADHD in neurocognitive tasks related to domains of attention, inhibitory control, information processing, and reward processing [1-16]. Varied ERP components were ever mentioned; they include P300, N100, N200, P100, P200, contingent neg-

Received: January 23, 2019/ Revised: May 2, 2019

Accepted: June 23, 2019

Address for correspondence: Yen Kuang Yang

Department of Psychiatry, National Cheng Kung University

Hospital, 138 Sheng Li Road, North Dist., Tainan 70403, Taiwan

E-mail: ykyang@mail.ncku.edu.tw

ORCID: https://orcid.org/0000-0001-9355-9636 ative variations, selection negativity, feedback negativity, late negativity, late positivity, error-related negativity, and error-related positivity [17]. The diverse results of altered ERP patterns in attention orientation and allocation, stimulus discrimination and processing, attention switching, and response inhibition suggest the heterogeneity of the underlying mechanism accounts for explicit symptoms in ADHD.

In addition to the association between altered ERPs and neurocognitive performance in ADHD subjects, varied form of ERP component was noted among subtypes of ADHD. For example, cue P300 amplitude could be used to differentiate subtypes of ADHD and was thought to be a neurophysiological marker of alerting deficits [18]. Other studies revealed ERP component as predictor of treatment response. Sangal et al. reported that the P300 topography could predict stimulant efficacy [19-21], and P300 amplitude is related to response to atomoxetine [22]. The potential use of ERP in diagnosis and tailored pharmacological treatment for ADHD subjects addressed

(c) This is an Open-Access article distributed under the terms of the Creative Commons Attribution Non-Commercial License (http://creativecommons.org/licenses/by-nc/4.0) which permits unrestricted non-commercial use, distribution, and reproduction in any medium, provided the original work is properly cited. 
the importance of further research in this area.

Biological heredity in ADHD and family vulnerability to ADHD-related brain dysfunction has also been noted. Shared characteristics in activation of prefrontal system and related neural circuits (e.g., frontal-cerebellar circuits, frontal-frontal-striatum circuits, frontal-parietal circuits, etc.) and executive dysfunction exist in unaffected siblings and parents of ADHD subjects [23-30]. McLoughlin et al. [31] ever mentioned about altered ERPs in fathers with ADHD children; they displayed significantly weaker error and conflict monitoring, as indexed by the smaller error negativity ( $\mathrm{Ne}$ ) and the N2 components. We speculated that shared characteristics could also be observed in ERPs. Exploring these characteristics and identifying biological markers of ADHD further are of clinical concern, not only for more understanding of pathophysiology but also for tailored individual treatment.

The aim of present study was to compare the ERPs and neurocognitive performances of parents with ADHD children and healthy controls. Since the P300 wave is of greatest interest and has been widely examined in ERP studies, we used the auditory oddball paradigm to evaluate the P300 wave complex in this study. We speculated that parents with ADHD children would have poorer neurocognitive function and differed ERPs pattern when comparing with healthy controls.

\section{METHODS}

\section{Participants}

We enrolled 13 healthy parents (9 males and 4 females) of children with ADHD from child psychiatry outpatient clinics of a National Cheng Kung University Hospital. The inclusion criteria were as follows: (1) have a child who fulfilled the Diagnostic and Statistical Manual of Mental Disorders, 4th edition (DSM-IV) criteria for child ADHD; (2) be aged between 20 and 60 years; (3) have no physical illness and stable vital signs; and (4) have no evidence of substance abuse/dependence as assessed during the clinical interview with the research psychiatrist at the time of enrollment.

A group of healthy controls $(n=13)$ with a similar age, sex, and number of years of education, without a child who fulfilled the DSM-IV criteria for child ADHD, was also enrolled from the community. Both the parents and healthy controls were confirmed by a senior psychiatrist to be free of any psychological disorder by the MiniInternational Neuropsychiatric Interview (MINI).

The exclusion criteria for all participants were as follows: (1) other co-morbid psychiatric illnesses or neurological illnesses; (2) mental retardation or intelligence quotient $(\mathrm{IQ})<70$.

Before any procedure was performed, written informed consent was obtained from the participants. The Ethics Committee for Human Research at the National Cheng Kung University Hospital approved the study protocol (A-BR-101-118).

\section{Event-related Potentials}

ERPs were recorded using an auditory oddball paradigm, based on methods that have been established previously [32]. Electroencephalograms (EEGs) were recorded using recording apparatus (NuAmps; Compumedics Neuroscan, El Paso, TX, USA). Recordings were performed using an electrocap (Neuroscan Quik-cap - 10/20 electrodes placement, $\mathrm{Ag} / \mathrm{AgCl}$ Sintered electrode; Comp umedics Neuroscan) in a sound-attenuated, electrically-shielded environment with an acoustic Celotex board. The number of EEG channels was 32. The EEG and eye channels were appropriately amplified (EEG Gain = 19, Sampling = 1,000/seconds, 22-bit A-to-D conversion) and filtered (band pass $=0.1-30 \mathrm{~Hz}$ ). Eye movements were recorded by an electrode lateral to both eyes, which was near the outer regions of the canthus. Auditory stimuli were delivered binaurally through headphones, and the interstimulus interval was between 1 and 2 seconds. Random target tones $(2,000 \mathrm{~Hz}$; probability, 0.2$)$ that differed from the non-target events $(1,000 \mathrm{~Hz}$; probability, 0.8 ) in pitch were established. Participants were instructed to look at the "+" target on the screen, and press the button as soon as possible when they identified one of the target tones. P300 potentials were recorded from the electrodes referenced linked to the mastoids. EEG epochs starting $150 \mathrm{~ms}$ before stimulus onset were averaged off-line by computer. Trials with electrooculography amplitudes over $50 \mu \mathrm{V}$ were excluded from the average. Subjects would receive 200 trials in total; those who completed fewer than 20 accepted trials for the target were excluded. The P300 amplitude was measured relative to the mean of the 100-ms prestimulus baseline, with peak latency defined as the time point associated with the maximum positive amplitude during the 200-400-ms inter- 
val following the stimulus. Both the amplitudes and the latencies were recorded by technicians.

\section{Wechsler Adult Intelligence Scale-Revised (WAIS-R)}

The WAIS-R [33] was used to evaluate the individuals' intelligence. This test gives a full-scale IQ (FIQ) and 2 different dimensions of IQ. The six-subtest short-form combination was composed of digit symbol, block design, object assembly, digit span, similarity, and arithmetic tests. We used the former three to obtain an estimated performance IQ, while the latter three were used to obtain an estimated verbal IQ. The mean FIQ score in this test is 100 (the standard deviation is 15).

\section{Wisconsin Card Sorting Test (WCST)}

To measure executive function, all participants were administered a 64-card version of the WCST, conducted by an experienced clinical psychologist. The participants were required to match response cards to four stimulus cards in one of three dimensions (color, form, or number) on the basis of sign feedback (correct or wrong). After sort- ing a series of 10 cards in one category, the subject was asked to sort the cards again in a different category. The definitions of the indices were as described in the WCST manual [34]. In this study, we examined the index of perseverative errors $[35,36]$, which is one of the most commonly-used indexes.

\section{Continuous Performance Test (CPT)}

The CPT [37] is a vigilance task requiring rapid information processing and the detection of briefly-presented target stimuli. A higher-processing-load version of the CPT has been proven to be useful for measuring an individual's attentive capacity and ability to process visual information. In this study, each test consisted of a 2 minute practice session, a non-masked task session, and a masked task session. During the masked session, a pattern of snow was used to toggle the background and foreground so that the image was visually distorted. Subject responses were recorded automatically on a diskette using a CPT machine (Sunrise Systems V2.26, Pembroke, MA, USA).

Table 1. Demographic data, event-related potential measurements, and cognitive functions of the parents of the parents of children with ADHD and their matched healthy controls

\begin{tabular}{|c|c|c|c|c|c|}
\hline & \multirow{2}{*}{$\begin{array}{l}\text { Parents of children with } \\
\qquad \text { ADHD }(n=13)\end{array}$} & \multirow{2}{*}{$\begin{array}{l}\text { Healthy controls } \\
\qquad(n=13)\end{array}$} & \multicolumn{3}{|c|}{ Statistics } \\
\hline & & & $\begin{array}{l}\text { Wilcoxon } \\
\text { signed rank test }\end{array}$ & $p$ value & Effect size \\
\hline Sex (Male/female) & $9 / 4$ & $9 / 4$ & - & - & - \\
\hline Age (yr) & $41.92 \pm 8.10$ & $41.86 \pm 8.54$ & 0.47 & 0.64 & 0.09 \\
\hline Years of education & $13.38 \pm 3.15$ & $13.23 \pm 3.06$ & 0.18 & 0.86 & 0.04 \\
\hline \multicolumn{6}{|l|}{ Amplitude $(\mu \mathrm{V})$} \\
\hline $\mathrm{Pz}$ & $6.71 \pm 4.42$ & $7.44 \pm 3.66$ & 0.59 & 0.55 & 0.12 \\
\hline $\mathrm{Cz}$ & $5.67 \pm 3.67$ & $7.01 \pm 4.24$ & 0.80 & 0.42 & 0.16 \\
\hline $\mathrm{Fz}$ & $5.48 \pm 3.78$ & $7.84 \pm 4.01$ & 1.57 & 0.12 & 0.31 \\
\hline \multicolumn{6}{|l|}{ Latency (ms) } \\
\hline $\mathrm{Pz}$ & $341.08 \pm 28.19$ & $331.46 \pm 30.96$ & 0.38 & 0.70 & 0.07 \\
\hline $\mathrm{Cz}$ & $339.00 \pm 22.83$ & $327.46 \pm 31.90$ & 1.08 & 0.28 & 0.21 \\
\hline $\mathrm{Fz}$ & $342.54 \pm 21.83$ & $320.77 \pm 27.28$ & 2.17 & 0.03 & 0.43 \\
\hline \multicolumn{6}{|l|}{ WAIS-R } \\
\hline Performance IQ & $111.15 \pm 13.95$ & $104.15 \pm 13.04$ & 1.71 & 0.09 & 0.34 \\
\hline Verbal IQ & $107.85 \pm 16.44$ & $101.23 \pm 15.79$ & 0.86 & 0.39 & 0.17 \\
\hline Full-scale IQ & $110.00 \pm 15.73$ & $102.38 \pm 14.03$ & 1.30 & 0.20 & 0.25 \\
\hline \multicolumn{6}{|l|}{ WCST } \\
\hline Perseveration errors & $19.85 \pm 13.63$ & $14.54 \pm 13.31$ & 1.08 & 0.28 & 0.21 \\
\hline \multicolumn{6}{|l|}{ СРТ } \\
\hline Unmasked d' & $4.47 \pm 0.69$ & $4.53 \pm 0.41$ & 0.80 & 0.42 & 0.16 \\
\hline Masked d' & $4.19 \pm 0.76$ & $3.85 \pm 0.64$ & 1.38 & 0.17 & 0.31 \\
\hline
\end{tabular}

Values are presented as number only or mean \pm standard deviation.

ADHD, attention deficit hyperactivity disorder; Pz, parietal; Cz, central; Fz, frontal; WAIS-R, Wechsler Adult Intelligence Scale-Revised; IQ, intelligence quotient; WCST, Wisconsin Card Sorting Test; CPT, continuous performance test. 
According to signal detection theory, the fundamental task in this test is to discriminate between the signal (target) and noise (non-target). The distribution of the attention test index, d', is a measure of the subject's ability to differentiate a signal from the background noise: a higher d' indicates a better processing capability.

\section{Statistics}

As the sample size was small and was matched for age, sex, and years of education, Wilcoxon signed-rank tests were used to examine the differences in age, years of education, ERP, and cognitive functions between groups. Spearman's $\rho$ correlations and partial correlations, controlling for age and sex [38,39], were carried out to examine the associations between ERP and cognitive functions. The level of significance was set at $p<0.05$ (two-tailed). All analyses were performed using SPSS software (version 17.0; SPSS Inc., Chicago, IL, USA).
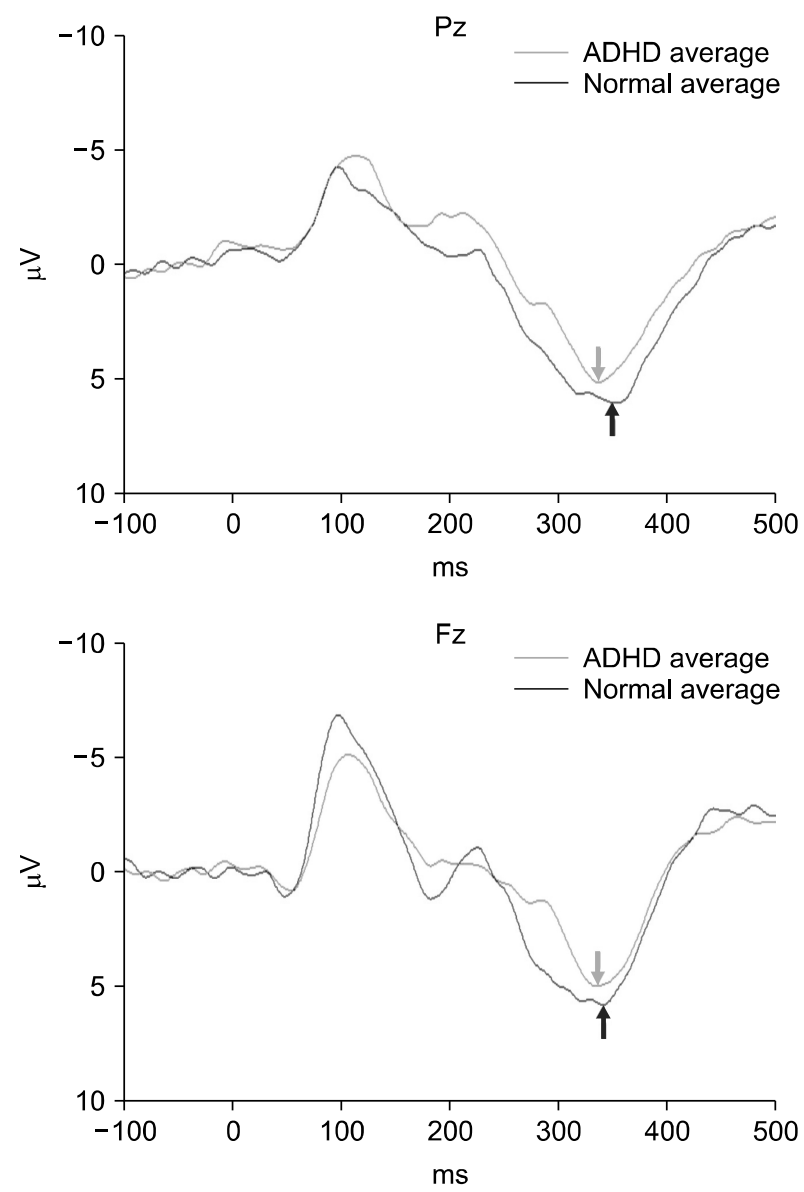

\section{RESULTS}

No significant differences were found in age, sex, years of education, or cognitive performance in the WAIS-R, WCST, and CPT between groups, as shown in Table 1. The grand average waveforms (Fig. 1) and the topographic

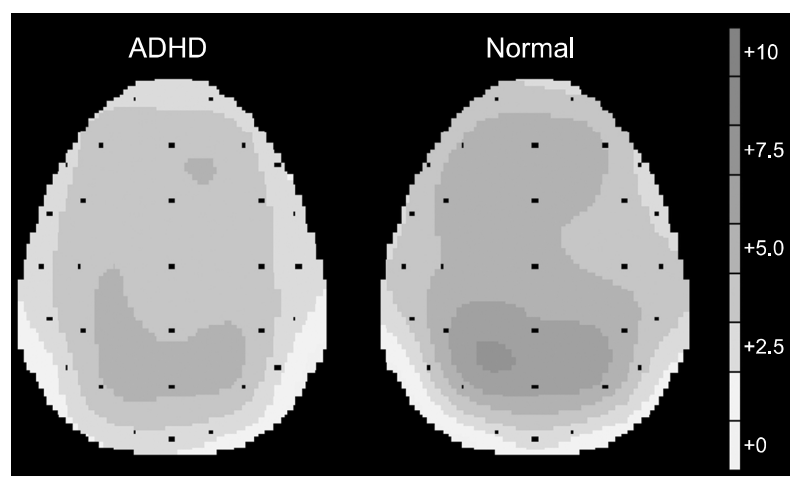

Fig. 2. The topographic maps for the two groups (duration 300 - 399 $\mathrm{ms})$.

ADHD, attention deficit hyperactivity disorder.

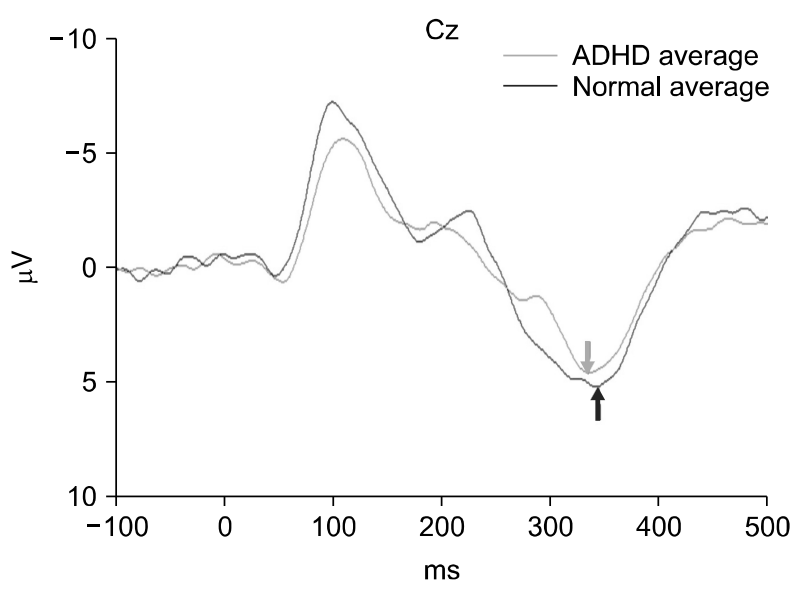

Fig. 1. The grand average waveforms for the two groups. $\mathrm{Pz}$, parietal; Cz, central; Fz, frontal. 
Table 2. Spearman's $\rho$ correlation between event-related potential and cognitive function in parents of children with attention deficit hyperactivity disorder

\begin{tabular}{|c|c|c|c|c|c|c|c|c|c|c|c|c|}
\hline & \multicolumn{6}{|c|}{ Amplitude $(\mu \mathrm{V})$} & \multicolumn{6}{|c|}{ Latency (ms) } \\
\hline & \multicolumn{2}{|c|}{$\mathrm{Pz}$} & \multicolumn{2}{|c|}{$\mathrm{Cz}$} & \multicolumn{2}{|c|}{$\mathrm{Fz}$} & \multicolumn{2}{|c|}{$\mathrm{Pz}$} & \multicolumn{2}{|c|}{$\mathrm{Cz}$} & \multicolumn{2}{|c|}{$\mathrm{Fz}$} \\
\hline & $\rho$ & $p$ value & $\rho$ & $p$ value & $\rho$ & $p$ value & $\rho$ & $p$ value & $\rho$ & $p$ value & $\rho$ & $p$ value \\
\hline \multicolumn{13}{|l|}{ WAIS-R } \\
\hline Performance IQ & -0.05 & 0.88 & 0.01 & 0.98 & -0.03 & 0.92 & 0.44 & 0.14 & 0.51 & 0.08 & 0.43 & 0.14 \\
\hline Verbal IQ & -0.24 & 0.43 & -0.01 & 0.97 & -0.02 & 0.96 & 0.33 & 0.28 & 0.25 & 0.41 & 0.19 & 0.52 \\
\hline Full-scale IQ & -0.21 & 0.48 & -0.03 & 0.93 & -0.01 & 0.96 & 0.45 & 0.12 & 0.43 & 0.15 & 0.33 & 0.27 \\
\hline \multicolumn{13}{|l|}{ WCST } \\
\hline Perseveration errors & -0.23 & 0.46 & -0.32 & 0.29 & -0.31 & 0.30 & 0.11 & 0.71 & -0.11 & 0.71 & -0.04 & 0.90 \\
\hline \multicolumn{13}{|l|}{ СРT } \\
\hline Unmasked d' & 0.42 & 0.16 & 0.35 & 0.25 & 0.33 & 0.27 & 0.35 & 0.24 & 0.21 & 0.49 & 0.20 & 0.52 \\
\hline Masked d' & -0.10 & 0.77 & -0.06 & 0.85 & -0.06 & 0.85 & 0.51 & 0.11 & 0.51 & 0.11 & 0.50 & 0.12 \\
\hline
\end{tabular}

Pz, parietal; Cz, central; Fz, frontal; WAIS-R, Wechsler Adult Intelligence Scale-Revised; IQ, intelligence quotient; WCST, Wisconsin Card Sorting Test; CPT, continuous performance test.

maps (Fig. 2) for the two groups were illustrated. However, the parents of children with ADHD had longer auditory P300 latency at Fz $(p=0.03)$ than the control group (Table 1). ERPs were not significantly correlated with cognitive function $(p>0.07)$ (Table 2), even when the age and sex was controlled $(p>0.07$, data were not shown) in the parents of children with ADHD.

\section{DISCUSSION}

Our results show that the parents of children with ADHD had longer auditory P300 ERP latency but did not have altered cognitive performance compared with their controls. This suggests that although there was no significant difference in neurocognitive performance between the two groups, a subtle alteration in the neurophysiological performance could exist as a potential candidate of biological marker in this population.

Latency is an indicator studying the functions of attention, since it varies with the effort of discriminating different stimulus [40]. It is closely related to stimulus discrimination and evaluation but not duration of response selection and execution [41]. Correlation between P300 latency and cognitive capability was mentioned [42]. It was increasing with aging and was thought to be related to dementing process $[43,44]$. Previous studies had discussed about the P300 latency in ADHD patients. ADHD children had longer visual P300 latency and lower P300 amplitude when comparing with controls, indicating reduced involvement in post-decisional processing [45]. A study from Taiwan also showed longer P300 latency in ADHD children [6]. Prolonged latency in ADHD children, and effect of methylphenidate on decreasing latency was reported [46]. Yamamuro et al. [47] had mentioned about prolonged P300 latency in ADHD children at fronto-central, central-parietal, and parietal positions, and positive correlation between the level of prolongation and severity of inattention symptoms. These results suggested the P300 latency as a neurophysiological marker in ADHD and might be changed under medication treatment. Our study showed a similar increase in the latency of P300 at Fz in ADHD healthy parents. To date, there has been no other study discussing P300 wave characteristic that has focused on healthy parents with ADHD offspring; our result suggested prolonged P300 latency as a candidate of shared marker in this population. However, there were also studies revealing no differences in P300 latency $[3,48]$. The discrepancy might be caused by the subjects' heterogeneity and different methodologies. Further studies using more comprehensive method with measuring of subcomponents of P300, or investigating the P300 waveform differences in subgroups with ADHD characters, are needed.

It is worth noting that there was no significant difference in P300 wave amplitude between ADHD parents group and controls in our study. Reduced P300 amplitudes in child and adult ADHD patients were mentioned in many previous studies although with different neurocognitive tasks, stimulus modalities, and heterogeneous methodologies [8-12,49-51]. This might reflect deficits in 
high level executive functions such as attention allocation [5], or ventral attention network dysfunction [16]. However, this tendency was not presented in healthy parents with ADHD offspring in our study. Putting these together, it might reflect the early stage of information processing, including the discrimination of different stimulus and stimulus evaluation, but not the late processing stage during attention task, as the main neurophysiological differences noted in this population.

The lack of a significant correlation between ERP alterations and neurocognitive performance, and the lack of deficits in cognitive function in healthy parents with ADHD offspring, might suggest that, as family members of ADHD patients, the underlying neural mechanisms of these tasks might be different in these individuals compared to the general population, despite the fact that they have no explicit attention, inhibition or executive dysfunction. We hypothesize that there are compensatory mechanisms in this population to maintain basic functionality. Since the neurophysiological alteration was subtle and mild in this study group compared with patients with clinically significant ADHD symptoms, the compensation from other parts of the neural processing was effective in adults with ADHD offspring to smoothly carry out the neurocognitive tasks. Another explanation is that the traditional neurocognitive tasks we used could not reflect subtle differences in explicit attention, inhibition control or executive function among the study group population. Considering our result of prolonged P300 latency, other neurocognitive tests involving the early information processing stage of attention task, like the selective attention task [52], should be considered in following study design. Further study is therefore required. The small sample size might be another reason for the lack of significant correlation between altered ERP and neurocognitive tasks.

There were several limitations in this study. Firstly, the sample size was small, and the significance of group difference was weak, therefore generalization of the results should be carried out with caution. Secondly, although the auditory oddball paradigm was used widely, subtle neurophysiological differences might not be elicited. Besides, other neurological tasks might be needed also to re-evaluate the correlation between the ERP alterations and neurocognitive performance. Thirdly, it would be better to check other ERP components that are known to be altered in ADHD to make the results more comprehen- sive. Finally, further studies that include ADHD adult patients as a comparison group are essential to explore the differences in ERPs and neurocognitive performance.

In conclusion, in parents with ADHD offspring, our findings provide preliminary evidence of altered neurophysiological correlates in the early information processing stage of attention task. Further investigation is needed to verify the association between neurophysiological correlates and explicit behaviors. Whether the prolonged P300 latency implicates the existence of potential biological marker and familiar association or not needs more exploration.

\section{- Acknowledgments}

This study was funded by the National Science Council of Taiwan (NSC 102-2420-H-006-007-MY2), the Ministry of Science and Technology, R.O.C. (MOST 104-2314-B006-053-MY2), and National Cheng Kung University Hospital (NCKUH-10104019 and NCKUH-10405033). The funding institutions of this study had no further role in the study design, the collection, analysis, and interpretation of data, the writing of this paper, or the decision to submit it for publication. The authors are indebted to Ms. Tsai Hua Chang from National Cheng Kung University Hospital.

\section{- Conflicts of Interest}

No potential conflict of interest relevant to this article was reported.

\section{- Author Contributions}

Corresponding author Yen Kuang Yang designed the study and wrote the protocol. Authors Ching-Lin Chu and Po See Chen contributed to the statistical analyses. Author Mei Hung Chi wrote the first draft of the manuscript. Authors I Hui Lee, Yi-Ting Hsieh, Kao Chin Chen, and Yen Kuang Yang managed the data collection. All authors interpreted the analysis of the results and helped to revise the manuscript.

\section{ORCID}

Mei Hung Chi

Ching-Lin Chu

I Hui Lee

Yi-Ting Hsieh

Ko Chin Chen https://orcid.org/0000-0001-5408-5466 https://orcid.org/0000-0002-6677-7053 https://orcid.org/0000-0003-2970-5744 https://orcid.org/0000-0001-6828-8280 https://orcid.org/0000-0001-8091-8820 
Po See Chen

https://orcid.org/0000-0003-4963-578X

Yen Kuang Yang

https://orcid.org/0000-0001-9355-9636

\section{REFERENCES}

1. Barry RJ, Johnstone SJ, Clarke AR. A review of electrophysiology in attention-deficit/hyperactivity disorder: II. Event-related potentials. Clin Neurophysiol 2003;114:184-198.

2. Shen IH, Tsai SY, Duann JR. Inhibition control and error processing in children with attention deficit/hyperactivity disorder: an event-related potentials study. Int I Psychophysiol 2011;81:1-11.

3. Lazzaro I, Anderson J, Gordon E, Clarke S, Leong J, Meares R. Single trial variability within the $P 300(250-500 \mathrm{~ms})$ processing window in adolescents with attention deficit hyperactivity disorder. Psychiatry Res 1997;73:91-101.

4. Johnstone SJ, Barry RJ, Anderson JW. Topographic distribution and developmental timecourse of auditory event-related potentials in two subtypes of attention-deficit hyperactivity disorder. Int I Psychophysiol 2001;42:73-94.

5. Senderecka M, Grabowska A, Gerc K, Szewczyk J, Chmylak R. Event-related potentials in children with attention deficit hyperactivity disorder: an investigation using an auditory oddball task. Int J Psychophysiol 2012;85:106-115.

6. Tsai ML, Hung KL, Lu HH. Auditory event-related potentials in children with attention deficit hyperactivity disorder. Pediatr Neonatol 2012;53:118-124.

7. Marquardt L, Eichele H, Lundervold AJ, Haavik J, Eichele T. Event-related-potential (ERP) correlates of performance monitoring in adults with attention-deficit hyperactivity disorder (ADHD). Front Psychol 2018;9:485.

8. Dhar M, Been PH, Minderaa RB, Althaus M. Distinct information processing characteristics in dyslexia and $A D H D$ during a covert orienting task: an event-related potential study. Clin Neurophysiol 2008;119:2011-2025.

9. McPherson DL, Salamat MT. Interactions among variables in the $P 300$ response to a continuous performance task in normal and ADHD adults. I Am Acad Audiol 2004; 15:666-677.

10. Prox V, Dietrich DE, Zhang Y, Emrich HM, Ohlmeier MD. Attentional processing in adults with $A D H D$ as reflected by event-related potentials. Neurosci Lett 2007;419:236-241.

11. Rodriguez PD, Baylis GC. Activation of brain attention systems in individuals with symptoms of $A D H D$. Behav Neurol 2007;18:115-130.

12. Wiersema R, van der Meere J, Antrop I, Roeyers H. State regulation in adult ADHD: an event-related potential study. J Clin Exp Neuropsychol 2006;28:1113-1126.

13. Herrmann MJ, Schreppel T, Biehl SC, Jacob C, Heine M, Boreatti-Hümmer $\mathrm{A}$, et al. Emotional deficits in adult $A D H D$ patients: an ERP study. Soc Cogn Affect Neurosci 2009;4:340345.

14. Fisher T, Aharon-Peretz J, Pratt H. Dis-regulation of response inhibition in adult attention deficit hyperactivity disorder
(ADHD): an ERP study. Clin Neurophysiol 2011;122:23902399.

15. Ibanez A, Cetkovich M, Petroni A, Urquina $H$, Baez $S$, Gonzalez-Gadea ML, et al. The neural basis of decision-making and reward processing in adults with euthymic bipolar disorder or attention-deficit/hyperactivity disorder (ADHD). PLoS One 2012;7:e37306.

16. Szuromi B, Czobor P, Komlósi S, Bitter I. P300 deficits in adults with attention deficit hyperactivity disorder: a metaanalysis. Psychol Med 2011;41:1529-1538.

17. Johnstone SJ, Barry RJ, Anderson JW, Coyle SF. Age-related changes in child and adolescent event-related potential component morphology, amplitude and latency to standard and target stimuli in an auditory oddball task. Int I Psychophysiol 1996;24:223-238.

18. Heinrich H, Busch K, Studer P, Erbe K, Moll GH, Kratz O. Refining the picture of reduced alerting responses in $A D H D$ a single-trial analysis of event-related potentials. Neurosci Lett 2014; 582:49-53.

19. Sangal JM, Sangal RB, Persky B. Abnormal auditory P300 topography in attention deficit disorder predicts poor response to pemoline. Clin Electroencephalogr 1995;26:204-213.

20. Sangal RB, Sangal JM. Attention-deficit/hyperactivity disorder: cognitive evoked potential (P300) topography predicts treatment response to methylphenidate. Clin Neurophysiol 2004; 115:188-193.

21. Sangal RB, Sangal JM. Attention-deficit/hyperactivity disorder: using P300 topography to choose optimal treatment. Expert Rev Neurother 2006;6:1429-1437.

22. Sangal RB, Sangal JM. Attention-deficit/hyperactivity disorder: cognitive evoked potential (P300) amplitude predicts treatment response to atomoxetine. Clin Neurophysiol 2005; 116:640-647.

23. Mulder MJ, Baeyens D, Davidson MC, Casey BJ, van den Ban $\mathrm{E}$, van Engeland $\mathrm{H}$, et al. Familial vulnerability to $A D H D$ affects activity in the cerebellum in addition to the prefrontal systems. J Am Acad Child Adolesc Psychiatry 2008;47:68-75.

24. Gau SS, Shang CY. Executive functions as endophenotypes in ADHD: evidence from the Cambridge Neuropsychological Test Battery (CANTAB). J Child Psychol Psychiatry 2010;51: 838-849.

25. Nigg JT, Blaskey LG, Stawicki JA, Sachek J. Evaluating the endophenotype model of ADHD neuropsychological deficit: results for parents and siblings of children with ADHD combined and inattentive subtypes. J Abnorm Psychol 2004;113: 614-625.

26. Casey BJ, Epstein JN, Buhle J, Liston C, Davidson MC, Tonev $\mathrm{ST}$, et al. Frontostriatal connectivity and its role in cognitive control in parent-child dyads with ADHD. Am J Psychiatry 2007:164:1729-1736.

27. Uekermann J, Kraemer M, Abdel-Hamid M, Schimmelmann BG, Hebebrand J, Daum I, et al. Social cognition in attentiondeficit hyperactivity disorder (ADHD). Neurosci Biobehav 
Rev 2010;34:734-743.

28. Rapin L, Poissant H, Mendrek A. Atypical activations of fronto-cerebellar regions during forethought in parents of children with ADHD. J Atten Disord 2017;21:1050-1058.

29. Poissant H, Rapin L, Mendrek A. Intergenerational transmission of fronto-parietal dysfunction during forethought in attention deficit/hyperactivity disorder: a pilot study. Psychiatry Res 2014;224:242-245.

30. Gong J, Xie J, Chen G, Zhang Y, Wang S. Neurological soft signs in children with attention deficit hyperactivity disorder: their relationship to executive function and parental neurological soft signs. Psychiatry Res 2015;228:77-82.

31. McLoughlin G, Albrecht B, Banaschewski T, Rothenberger A, Brandeis D, Asherson $\mathrm{P}$, et al. Performance monitoring is altered in adult ADHD: a familial event-related potential investigation. Neuropsychologia 2009;47:3134-3142.

32. Picton TW, Bentin S, Berg P, Donchin E, Hillyard SA, Johnson $\mathrm{R} \mathrm{Jr}$, et al. Guidelines for using human event-related potentials to study cognition: recording standards and publication criteria. Psychophysiology 2000;37:127-152.

33. WAIS-R manual: Wechsler adult intelligence scale-revised. New York:Psychological Corporation; 1981.

34. Heaton RK, Chelune G, Talley J, Kay G, Curtiss G. Wisconsin Card Sorting Test (WCST): manual: revised and expanded. Odessa:Psychological Assessment Resources; 1993.

35. Stratta P, Mancini F, Mattei P, Daneluzzo E, Casacchia M, Rossi A. Association between striatal reduction and poor Wisconsin card sorting test performance in patients with schizophrenia. Biol Psychiatry 1997;42:816-820.

36. Volkow ND, Gur RC, Wang GJ, Fowler JS, Moberg PJ, Ding $\mathrm{YS}$, et al. Association between decline in brain dopamine activity with age and cognitive and motor impairment in healthy individuals. Am J Psychiatry 1998;155:344-349.

37. Hsieh PC, Chu CL, Yang YK, Yang YC, Yeh TL, Lee IH, et al. Norms of performance of sustained attention among a community sample: Continuous Performance Test study. Psychiatry Clin Neurosci 2005;59:170-176.

38. Melynyte S, Wang GY, Griskova-Bulanova I. Gender effects on auditory P300: a systematic review. Int I Psychophysiol 2018;133:55-65.

39. van Dinteren R, Arns M, Jongsma ML, Kessels RP. P300 deve/opment across the lifespan: a systematic review and metaanalysis. PLoS One 2014;9:e87347.

40. Picton TW. The P300 wave of the human event-related potential. J Clin Neurophysiol 1992;9:456-479.
41. Magliero A, Bashore TR, Coles MG, Donchin E. On the dependence of $\mathrm{P} 300$ latency on stimulus evaluation processes. Psychophysiology 1984;21:171-186.

42. Houlihan M, Stelmack R, Campbell K. Intelligence and the effects of perceptual processing demands, task difficulty and processing speed on P300, reaction time and movement time. Intelligence 1998;26:9-25.

43. Fjell AM, Walhovd KB. P300 and neuropsychological tests as measures of aging: scalp topography and cognitive changes. Brain Topogr 2001;14:25-40.

44. Vecchio F, Määttä S. The use of auditory event-related potentials in Alzheimer's disease diagnosis. Int I Alzheimers Dis 2011;2011:653173.

45. Strandburg RJ, Marsh JT, Brown WS, Asarnow RF, Higa J, Harper R, et al. Continuous-processing--related event-related potentials in children with attention deficit hyperactivity disorder. Biol Psychiatry 1996;40:964-980.

46. Ozdag MF, Yorbik O, Ulas UH, Hamamcioglu K, Vural O. Effect of methy/phenidate on auditory event related potential in boys with attention deficit hyperactivity disorder. Int J Pediatr Otorhinolaryngol 2004;68:1267-1272.

47. Yamamuro K, Ota T, lida J, Nakanishi Y, Suehiro Y, Matsuura $\mathrm{H}$, et al. Event-related potentials correlate with the severity of child and adolescent patients with attention deficit/hyperactivity disorder. Neuropsychobiology 2016;73:131-138.

48. Yoon $\mathrm{HH}$, lacono WG, Malone SM, Bernat EM, McGue M. The effects of childhood disruptive disorder comorbidity on P3 event-related brain potentials in preadolescents with ADHD. Biol Psychol 2008; 79:329-336.

49. Satterfield JH, Schell AM, Nicholas TW, Satterfield BT, Freese TE. Ontogeny of selective attention effects on event-related potentials in attention-deficit hyperactivity disorder and normal boys. Biol Psychiatry 1990;28:879-903.

50. Winsberg BG, Javitt DC, Silipo GS, Doneshka P. Mismatch negativity in hyperactive children: effects of methylphenidate. Psychopharmacol Bull 1993;29:229-233.

51. Kemner C, Verbaten MN, Koelega HS, Buitelaar JK, van der Gaag RJ, Camfferman G, et al. Event-related brain potentials in children with attention-deficit and hyperactivity disorder: effects of stimulus deviancy and task relevance in the visual and auditory modality. Biol Psychiatry 1996;40:522-534.

52. Jonkman LM, Kenemans JL, Kemner C, Verbaten MN, van Engeland $\mathrm{H}$. Dipole source localization of event-related brain activity indicative of an early visual selective attention deficit in ADHD children. Clin Neurophysiol 2004; 115:1537-1549. 